\title{
HYDROXYCHLOROQUINE IMPAIRS PRIMARY HUMORAL RESPONSE AFTER YELLOW FEVER VACCINATION IN PRIMARY SJÖGREN'S SYNDROME
}

Ketty Lysie Libardi Lira Machado ${ }^{1, \star}$, Ismael Artur da Costa-Rocha², Samira Tatiyama Miyamoto ${ }^{1}$, Priscila Costa Martins Rocha ${ }^{1}$, Erica Vieira Serrano ${ }^{1}$, Ana Paula Espíndula Gianordoli ${ }^{1}$, Larissa Carvalho Caser $^{1}$, Thays Zanon Casagrande ${ }^{1}$, Laura Gonçalves Rodrigues Aguiar ${ }^{1}$, Sávio Carvalho Deotti ${ }^{1}$, Ana Carolina Campi-Azevedo², Andréa Teixeira-Carvalho², Vanessa PeruhypeMagalhães ${ }^{2}$, Maria de Fatima Bissoli ${ }^{1}$, Sheila Maria Barbosa de Lima ${ }^{3}$, Adriana de Souza Azevedo Soares ${ }^{4}$, Gisela Freitas Trindade ${ }^{2}$, Lícia Maria Henrique da Mota ${ }^{4}$, Olindo Assis Martins-Filho², Valéria Valim Cristo ${ }^{1}$

1.Universidade Federal do Espírito Santo, Vitória (ES), Brazil; 2.Fundação Oswaldo Cruz, Belo Horizonte (MG), Brazil; 3.Fundação Oswaldo Cruz, Rio de Janeiro (RJ), Brazil; 4.Ministério da Saúde, Brasília (DF), Brazil.

*Corresponding author: kettylysie@yahoo.com.br

\section{BACKGROUND}

Yellow fever (YF) vaccination is suggested to induce a large number of adverse events and suboptimal responses in patients with autoimmune diseases (AID) associated with immunosuppressors. Hydroxychloroquine (HCQ) is an immunomodulatory drug with antiviral properties like lysosomal activity and autophagy, leading to a decrease of antigen processing. It is also known to interfere with endosomal Toll-like receptors signaling and cytosolic sensors of nucleic acids, which result in a decreased cellular activation and thereby a lower type I interferons and inflammatory cytokine secretion. The present study aimed to investigate whether the use of hydroxychloroquine would impact the overall performance of planned 17DD-YF primary vaccination of primary Sjögren's syndrome (pSS).

\section{METHODS}

This was a prospective study, carried out between March 2017 and July 2017 in Vitória, Espírito Santo, Brazil. All participants received the 17DD-YF primary vaccination (Bio-Manguinhos/Fiocruz) during the 2017 Brazilian YF vaccination campaign. A total of 51 volunteers with primary Sjögren's syndrome and 51 healthy donors (HD) were included. The YF-plaque reduction neutralization test (PRNT $\geq 1: 50$ ), YF viremia (RNAnemia) by qRT-PCR and serum biomarkers analyses were performed at baseline and subsequent time-points (D0/D3-4/D5-6/D7/D14-D28).

\section{RESULTS}

After excluding those with positive PRNT ( $>1: 50$ ) at baseline, $23 \mathrm{HD}$ and $34 \mathrm{pSS}$ were analyzed. Groups were similar to mean age ( $57.2 \pm 14.46$ vs. $55.29 \pm 13.73, p=0.608)$, female predominance in $\mathrm{pSS}(69.5 \%$ vs. $100 \%, p=0.0004)$. In pSS group those who were using or not HCQ (HCQ vs. non-HCQ group) were compared. The HCQ group ( $n=16)$ were younger $(50.6 \pm 12.80$ vs. $59.5 \pm 13.46, p=0.05$ ), $25 \%$ used methotrexate, $6.25 \%$ leflunomide and $6.25 \%$ sulfasalazine, in addition to HCQ. The non-HCQ group ( $n=18$ ) only $16 \%$ were using methotrexate. The pSS showed PRNT titers and seropositivity rates similar as compared to $\mathrm{HD}$ (GeoMean $=440$ vs. 238, $p=0.11 ; 96 \%$ vs. $82 \%, p=0.13$ ). However, the HCQ group exhibited lower seroconversion rates as compared to HD (GeoMean $=440$ vs. $161, p=0.04 ; 96 \%$ vs. $69 \%, p=0.02$ ) and Non-HQC (GeoMean = 337 vs. 161, $p=0.582$; $94 \%$ vs. $69 \%, p=0.049$ ) (Figure 1). No differences in YF viremia were observed amongst subgroups.

\section{CONCLUSION}

Hydroxychloroquine decreases humoral immune response after primary yellow fever vaccination. Future studies about biomarker kinetic can clarify the evolved mechanisms.

\section{KEYWORDS}

Sjögren’s syndrome, Hydroxychloroquine, Yellow fever vaccine. 

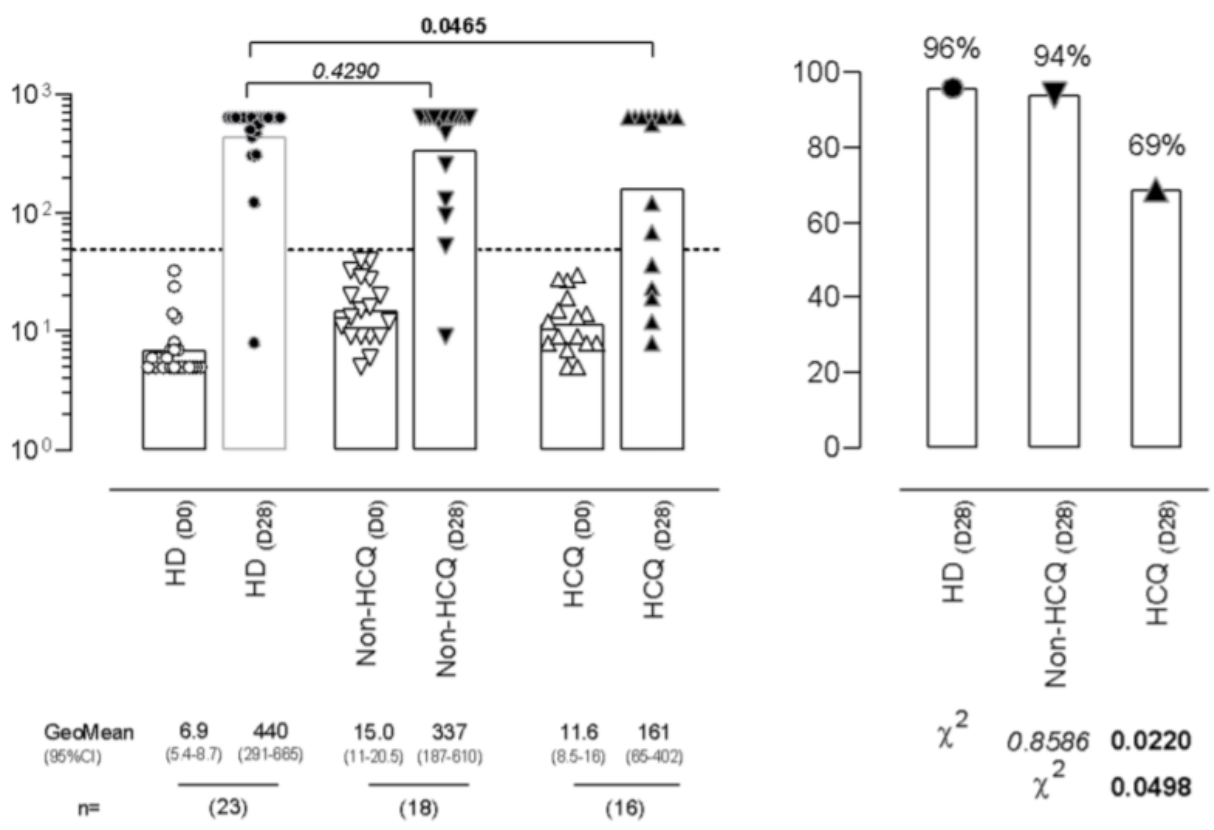

Figure 1. Neutralizing antibody titers and seropositivity rates in Sjögren's syndrome patients categorized according to the use of non-HCQ or HCQ immunotherapy. 